\title{
GENERATION OF THz-RADIATION BY DIFFERENCE- FREQUENCY MIXING AT ONE- AND TWO-PHOTON RESONANCES
}

\author{
E. Gaižauskas ${ }^{a}$, O. Balachninaite ${ }^{\text {a }}$, and O. Khasanov ${ }^{\mathrm{b}}$ \\ ${ }^{a}$ Laser Research Center, Vilnius University, Sauletekio 10, LT-10222 Vilnius, Lithuania \\ ${ }^{b}$ Scientific-Practical Materials Research Center of the National Academy of Sciences of Belarus, P. Brovki 19, 220072, \\ Minsk, Belarus \\ E-mail: eugenijus.gaizauskas@ff.vu.lt
}

Received 4 March 2014; accepted 29 May 2014

\begin{abstract}
In this work, difference-frequency generation is theoretically analysed for the three-level quantum system, having forbidden in dipole approximation electronic and optically active vibration transitions from the ground state. Excitation of coherent phonon polaritons wave in the terahertz frequency range by an ultrashort optical pulse, being in the visible or near-infrared spectral regions, and injected pulse with frequency almost twice that of the pump is considered. Dynamics of terahertz radiation arising during excitation of both electronic and vibrational coherences at the two-photon and combined resonances in the ensemble of three-level quantum systems was evaluated.
\end{abstract}

Keywords: terahertz radiation, difference-frequency generation, two-photon resonance, coherent light and matter interaction

PACS: $42.6+5 .-\mathrm{k}, 71.36 .+\mathrm{c}, 78.20 .-\mathrm{e}$

\section{Introduction}

After the first demonstration of optical methods [1-3] for creating terahertz $(\mathrm{THz})$ radiation, developments in the field of optical rectification (OR) methods have intensified in recent years among various groups of researchers (see e. g. [他] for a review) due to increased demand for high-energy broadband pulses in the $\mathrm{THz}$ frequency range (ranging from tens to thousands of micrometres for corresponding wavelengths). The essence of the OR methods involves directing the ultrashort optical pulses at a suitable nonlinear material (such as certain semiconductors, or air), causing emission of the $\mathrm{THz}$ wave at the frequency diffrence of the spectral components from pump beams. Usually, depending on symmetry of the media, a three- or four-wave rectification model was used for a description of the underlying physics of the generation of $\mathrm{THz}$ radiation. Specifically, in the case of the centrosymmetric media the generation of the $\mathrm{THz}$ wave results from the third-order nonlinear process of fourwave mixing (FWM) and can be interpreted as

$$
\mathcal{E}_{\mathrm{THz}} \sim \chi^{(3)} \mathcal{\varepsilon}_{\omega}^{2} \varepsilon_{2 \omega}^{*} \cos (\varphi)
$$

whereas in non centro-symmetric media the secondorder nonlinearity (and three-wave mixing process, respectively) responds for the generation of the $\mathrm{THz}$ wave:

$$
\mathcal{E}_{\mathrm{THz}} \sim \chi^{(2)} \mathcal{E}_{\omega} \boldsymbol{\varepsilon}_{\omega}^{*} .
$$

Here $\varepsilon_{2 \omega(\omega)}$ denote complex amplitudes; $\chi^{(3)}, \chi^{(2)}$ are the second- and third-order nonlinear susceptibilities, respectively, and $\varphi$ stands for the relative phase diffrence between the pump waves oscillating at frequencies $\omega$ and $2 \omega$.

Despite a tremendous interest in and efforts towards developing the capabilities of OR methods, to the best of our knowledge, optical-to- $\mathrm{THz}$ conversion efficiencies achieved by OR methods typically appear in the range of $10^{-5}-10^{-4}$, and only very recently $\sim 10^{-3}$ conversion efficiency was achieved in the stoichiometric lithium niobate crystal through excitation by high-energy $100 \mathrm{~mJ}$ picosecond pulses [5]. To extend this discussion, it is generally accepted that not only the Manley-Rowe conversion limit (which allows, in principle, at least $\sim 10^{-2}$ conversion efficiency from a wavelength of one to one hundred micrometres), but 
also interaction process requirements (including strict velocity matching constraints and prerequisite low absorption) are necessary for the efficient generation of the $\mathrm{THz}$ wave. To overcome these dificulties a few ideas have been proposed, such as using quasiphase-matched (QPM) materials with a periodically inverted sign of second-order susceptibility [6], cascading processes of $\mathrm{THz}$ generation [8, 8], velocity matching under conditions of self-induced transparency (SIT) [9], when the group velocity of the pump is known to be considerably slowed. Again, the idea of using OR under excitation of nonlinear media with a tilted front of the pulse was proposed in [10].

It should be noted that most efforts to generate high-energy broadband $\mathrm{THz}$ pulses were directed toward new implementations for the third-order nonlinear wave mixing in non centro-symmetric media. In general, this is a sensible choice, because usually second-order nonlinearity prevails over the third-order nonlinearity. On the other hand, it is known that normally susceptibilities enhance when mixing frequencies approache resonance; one can make a successive use of wave-mixing processes in the vicinity of resonances. However, using second-order nonlinearity and three-wave mixing one comes up against absorptive losses, because the frequency of the pump pulse appears at one photon resonance and the wave mixing as such will drop rapidly. In contrast to this, exploring two-photon resonances and FWMin centrosymmetric media the energy of the two-photon resonant ultrashort pulse may be kept constant for a relatively long propagation distance. Indeed, coherent interaction in many-level quantum systems provides promising concepts for the generation of electromagnetic (EM) radiation: amplification without inversion and relatively the possibility of tailoring material dispersion [11-13]. The recently demonstrated experimental technique [14] for efficient FWMin K atomic vapors exploiting one- and two-photon resonances should be regarded as an example of enhanced difference frequency generation (DFG) in a quantum ensemble. Therefore, natural questions about the role and significance of the induced vibrational coherence for generation of the EM radiation in the $\mathrm{THz}$ frequency range should be raised.

This paper attempts to describe the dynamics of the $\mathrm{THz}$ radiation generation in an ensemble of threelevel quantum systems (TLQSs). Specifically, in Section 2 we start with a short description of the coherent FWM in a TLQS possesing two-and one-photon resonances. In Section 3 the method and solution of the Maxwell equation for the propagation of the $\mathrm{THz}$ wave is described. Finally, in Section 4 we present the main results, and Section 5 concludes the paper.

\section{Background of nonperturbative description of FWM in TLQS experiencing one- and two-photon resonances}

Consider a coherent two-photon resonant femtosecond pulse interaction with the TLQS as it is shown in Fig. 1. Suppose that the following conditions for the frequency $\omega_{L}$ and width $\tau_{L}$ of the pump pulse are valid: $\tau_{L}<<T_{2}^{i j}, T_{1}^{i j},\left|2 \omega_{L}-\omega_{31}\right|=\Delta_{L}$, where $\omega_{31}$ corresponds to the transition frequency between $|1\rangle$ and |3〉 quantum states, $\Delta_{L}$ denotes frequency detuning from two-photon resonance, and $T_{2}^{i j},\left(T_{1}^{i j}\right)$ is transverse (longitudinal) relaxation time for transition $|i\rangle \Rightarrow|j\rangle$. The polarization at the optically active (in the $\mathrm{THz}$ range) transition $|1\rangle \Rightarrow|2\rangle$ is induced by a probe field (having carrier frequency $\omega_{P}$ ) driven subsequently to the laser (pump) pulse.

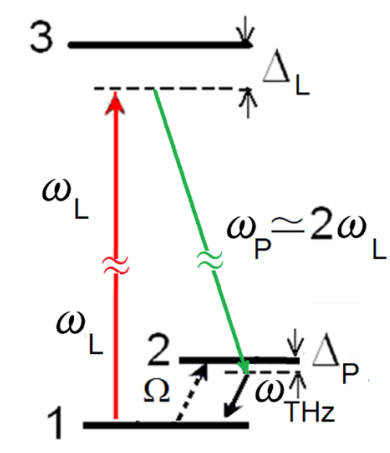

Fig. 1. (Colour online.) Two- and one-photon excitations in a three-level configuration of TLQS. A relative strong laser pulse at frequency $\omega_{L}$ excites the two-photon transition $|1\rangle \Rightarrow|3\rangle$ and a weak probe having frequency $\omega_{P}$ nm drives the transition $|3\rangle \Rightarrow|2\rangle$. Coherent phonon-polariton excitation at the transition $|1\rangle \Rightarrow|2\rangle$ radiates in $\mathrm{THz}$ range.

Owing to a number of papers [15-21] having been published that contain the main aspects of coherent laser light-matter interaction under twophoton resonance, we will not repeat details of the derivation of equations of motion for fields and material variables here. Instead, taking into account the relatively low efficiency of the process under consideration we assume that the pump pulse propagates without depletion. In this case, a slowly varying complex envelope $\varepsilon_{L}(z, \tau)$ of the pump pulse propagating at two-photon resonance with group velocity $v_{\mathrm{g}}$ reads $[15,16]$ : 


$$
\mathcal{E}_{L}^{2}(z, \tau)=\frac{\varepsilon_{L}^{2}(0, \tau)}{1+2 K_{2} z \sin \psi(0, \tau)+K_{2} z[1-\cos \psi(0, \tau)]},
$$

were $\psi(z, \tau)-r_{13} / 2 \hbar \int_{-\infty}^{\tau} \varepsilon_{L}^{2}\left(z, t^{\prime}\right) \mathrm{d} t^{\prime}, r_{13}$ is the matrix element for two-photon resonant transition, $z$ stands for propagation coordinate, $\tau=t-z / v_{\mathrm{g}}$, and the physical notion of $K_{2}$ is the two-photon absorption coefficient. Accordingly, $1 / K_{2}$ appears as a two-photon absorption length, to which the propagation distance will be normalized when presenting our results. The solution of Eq. (3) shows that the energy of the pulse with $\pi<\psi(z, \infty)<3 \pi / 2$ is absorbed and tends to the steadystable solitonic $2 \pi$-pulse with the Lorentzian profile:

$$
\varepsilon_{L}^{2}(z, \tau)=\frac{4 \hbar}{r_{13} \tau_{L}}\left(1+\frac{\tau^{2}}{\tau_{L}^{2}}\right)^{-1} .
$$

Accordingly, the group velocity of the $2 \pi$-pulse is related with its duration:

$$
\frac{1}{v_{\mathrm{g}}}-\frac{n_{\omega_{L}}}{c}=2 K_{2} \tau_{L} .
$$

From Eq. (5) one concludes that the group velocity of the optical pump pulse can be matched to the velocity of $\mathrm{THz}$ radiation in the case when the former exceeds the highest phase velocity of the $\mathrm{THz}$ waves in the material.

To continue in this vein, assuming $\Delta_{L}=0$ for coherence $\rho_{13}$ induced at two-photon resonant transition by the gaussian pump pulse we get:

$$
\rho_{13}(z, \tau)=\frac{\mathrm{i}}{2} \sin \psi(0, \tau)=\frac{\mathrm{i} \sqrt{\pi}}{2}\left[1+\operatorname{erf}\left(\tau / \tau_{L}\right)\right] .
$$

Now, let the probe pulse $\varepsilon_{P}\left(z, t-\tau_{D}\right)$ having the frequency almost twice higher than that of the pump to be injected with a time delay $\tau_{D}$. Under non-depleted pump approximation (when the changes to the pump pulses are disregarded), the nonlinear lowfrequency polarization induced by both pulses (pump and injected) in the vicinity of resonant transition $|1\rangle \Rightarrow|2\rangle$ appears to be [17, 21]:

$$
\tilde{r}_{13} N \mathcal{E}_{P}^{*}\left(z, t-\tau_{D}\right) \rho_{31}(z, \tau)=\tilde{r}_{13} P_{O R}(z, \tau),
$$

where $\widetilde{r}_{13}$ denotes the two-photon transition matrix element for waves having frequencies $\omega_{P}$ and $\Omega_{\mathrm{THz}}$, and $N$ stands for the concentration of the TLQSs.

The polarization wave given by Eq. (7) propagates with group velocity $v_{\mathrm{g}}=c /\left(n_{\omega_{L}}+2 K_{2} \tau_{L}\right)$. Because of the finite decay time of the coherence $\rho_{13}$, two-photon resonance enables wave-mixing even after the pulses are fully separated in space, whereas in the case of offresonance illumination wave-mixing appears only as long as the perturbing fields overlap.
As has been noted, efficient $\mathrm{THz}$ wave generation requires fulfillment of velocity matching between the phase velocities of $\mathrm{THz}$ waves and the group velocity of the optical pulse. The phase velocities of $\mathrm{THz}$ waves depend on the refractive index. Under one-photon resonance approximation the dielectric constant $\epsilon(\omega)$, which accounts for the linear polarizability of the resonant transition $|1\rangle \Rightarrow|2\rangle$, is given by the following expression:

$$
\epsilon(\omega)=\epsilon_{\infty}+\frac{\left(\epsilon_{0}-\epsilon_{\infty}\right) \Omega}{\Omega^{2}-\omega^{2}+\mathrm{i} \gamma \omega},
$$

where $\epsilon_{\infty}$ and $\epsilon_{0}$ are low- and high-frequency dielectric constants, respectively, and is the damping rate for the low-frequency coherence. Because for transparent media the refractive index always decreases when the frequency of the EM excitation decreases, inequality $\sqrt{\epsilon_{0}}>n\left(\omega_{L}\right)$ holds for excitation of $\mathrm{THz}$ pulses by optical and near-infrared pulses in the normal dispersion region. Therefore, the possibility of adjusting propagation velocity of the pump to $\mathrm{THz}$ waves due to two-photon resonant SIT delayed pump pulse is advantageous for $\mathrm{THz}$ wave generation.

Furthermore, we will consider planar wave propagation in the $z$-direction and the pump non-depletion situation. The equation (scalar form) for the Fourier component of the generated field follows directly from Maxwell's equations and in our case reads as follows:

$$
\begin{aligned}
& \frac{\partial^{2} \widetilde{\mathcal{E}}_{\mathrm{THz}}(z, \omega)}{\partial z^{2}}+\kappa^{2} \widetilde{\mathcal{E}}_{\mathrm{THz}}(z, \omega)= \\
& -\frac{4 \pi \omega^{2} \widetilde{\boldsymbol{r}}_{13} N}{c^{2}} \widetilde{\mathscr{P}}_{O R}(z, \omega) \mathrm{e}^{-\mathrm{i} \omega z / v_{\mathrm{g}}} .
\end{aligned}
$$

Here the (longitudinal) wavenumber $\kappa=\omega \sqrt{\epsilon(\omega)} / c$ of the $\mathrm{THz}$ wave was introduced, and the right hand side of Eq. (9) bears from the (Fourier transformed) nonlinear amplitude $\mathcal{P}_{O R}(\tau)$ induced by the pump and probe field in the $\mathrm{THz}$ frequency range:

$$
\widetilde{\mathcal{P}}_{O R}(\omega)=\int_{-\infty}^{\infty} \mathcal{P}_{O R}(\tau) \mathrm{e}^{-\mathrm{i} \omega \tau} \mathrm{d} \tau .
$$

As was noted above, the matrix element $r_{13}$ in Eq. (7) characterises the strength of the two-photon resonant transition induced by the (off-resonant) pump field, whereas $\widetilde{r}_{13}$ corresponds to the twophoton transition induced by the injected and $\mathrm{THz}$ waves, both having frequencies in the vicinity of one-photon resonances. Therefore, $\widetilde{r}_{13}$ prevails over the $r_{13}$ [22, 23], and nonlinear polarisation causes the amplification of the $\mathrm{THz}$ wave (amplification without inversion) even under the initial condition of the occupied lowest state $|1\rangle$. In order to analyse the amplification process of $\mathrm{THz}$ radiation in the TLQS 
quantum ensemble, we will use the analytical solution of Eq. (9) for the case of semi-infinite media (in the absence of the exit surface) [24-26. After normalising the propagation coordinate (to two-photon absorption length) and amplitudes (to the maximum amplitude of the pump field), we obtain:

$$
\begin{aligned}
& \widetilde{\mathcal{E}}_{\mathrm{THz}}(z, \omega)=\frac{q \widetilde{\mathcal{P}}_{O R}(\omega)}{\epsilon(\omega)-n_{\mathrm{g}}^{2}} \times \\
& {\left[\frac{1+n_{\mathrm{g}}}{1+\sqrt{\epsilon(\omega)}} \mathrm{e}^{-\mathrm{i} \omega \sqrt{\epsilon(\omega) z / c}}-\mathrm{e}^{-\mathrm{i} \omega z / v_{\mathrm{g}}}\right],}
\end{aligned}
$$

where $q=\widetilde{r}_{13} \omega_{\mathrm{THz}} /\left(r_{13} \omega_{L}\right)$ and $n_{\mathrm{g}}=c / v_{\mathrm{g}}$. The evolution of the $\mathrm{THz}$ wave $\mathcal{E}_{\mathrm{THz}}(z, \tau)$ in space and time can be found by taking the inverse transform of the given Fourier components of the $\mathrm{THz}$ wave at hand:

$$
\varepsilon_{\mathrm{THz}}(z, \tau)=\int_{-\infty}^{\infty} \widetilde{\varepsilon}_{\mathrm{THz}}(z, \omega) \mathrm{e}^{\mathrm{i} \omega \tau} \mathrm{d} \omega,
$$

and will be used for the evaluation of numerical examples of $\mathrm{THz}$ radiation generation by FW DFM.

\section{Numerical examples of THz generation by FW DFM and discussions}

In the previous section, we considered the ensemble of TQLS level systems with forbidden (in dipole approximation) electronic and allowed vibrational transitions from the ground state. The mentioned electronic transition is driven via pump pulse at twophoton resonance, and the propagation coordinate is normalized to the two-photon absorption length $K_{2}$ for a weak pulse (i. e. $\psi(0, \infty)<<\pi)$. In order to illustrate the theoretical results we calculated several forms of the $\mathrm{THz}$ wave excited in the lower-frequency branch $\left(\omega_{\mathrm{THz}}<\omega_{\mathrm{TO}}\right)$ of polariton dispersion for different regimes of the nonlinear polarization propagation sketched in Fig. 2.

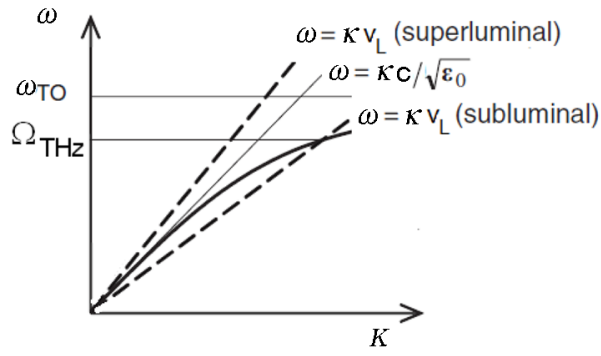

Fig. 2. Lower-frequency branch of polariton dispersion (bold solid line) and dispersions of free EM waves in cases of the subluminal and superluminal propagation (shown by dashed lines). Velocity matching condition for the frequency $\Omega_{\mathrm{THz}}$ appears to be satisfied at the intersection point of the dispersion curve and the line $\omega=\kappa v_{g}$ in the subluminal case.
Specifically, illustrations are given for the cases when induced nonlinear polarization $\mathcal{P}_{O R}(z, \tau)$ moves faster (weakly-superluminal and superluminal excitation) and slower (subluminal excitation) as compared to velocities of $\mathrm{THz}$ waves.

Because Eq. (9) does not contain singularities in the case of superluminal excitation of the $\mathrm{THz}$ wave (i. e. when condition $n_{L}^{2}<\epsilon(\omega)$ is satisfied), it may be simplified ignoring frequency dependence of $\epsilon(\omega)$. In this case one gets [25]:

$$
\begin{aligned}
& \mathcal{E}_{\mathrm{THz}}(z, t)=\frac{4 \pi q}{\epsilon-n_{L}^{2}} \times \\
& {\left[\frac{1+n_{L}}{1+\sqrt{\epsilon}} \mathcal{P}_{O R}(t-\sqrt{\epsilon} z / c)-\mathscr{P}_{O R}\left(t-z / v_{\mathrm{g}}\right)\right] .}
\end{aligned}
$$

For illustration of $\mathrm{THz}$ radiation generation dynamics, in Fig. 3 we compare two cases, which can be regarded as weakly $\left(\sqrt{\epsilon}=1.01 n_{L}=3.0\right)$ and strongly $\left(\sqrt{\epsilon}=2.0 n_{L}=2.5\right)$ superluminal regimes. The duration of both the pump and the injected pulses are taken to be equal: $\tau_{L}=\tau_{P}=0.15$ ps. Other parameters read as follows: $\Delta=\tau_{D}=0, \psi_{L}=\pi / 4, \psi_{P}=\pi / 40, \gamma=\pi=$ $100 \mathrm{THz} ; q=1$.

As a main difference between the two cases of $\mathrm{THz}$ wave generation dynamics depicted in Fig. 3 separate propagation of two pulses in the strongly superluminal regime of excitation should be noted. The pulses are

(a)

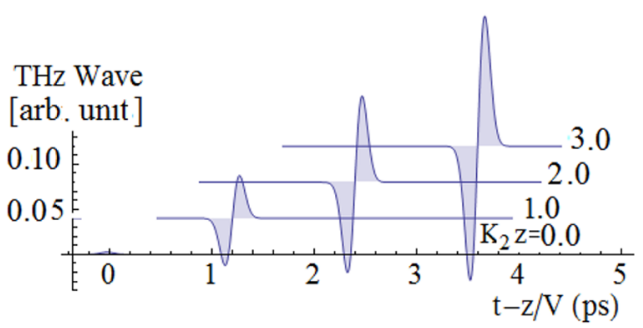

(b)

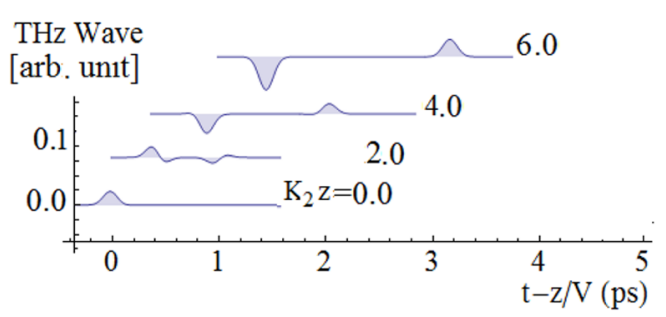

Fig. 3. Dynamics of THz radiation generation under superluminal propagation of the $\mathrm{THz}$ polarization source given by Eq. (7). Amplitudes of THz radiation are shown in the vertical offsets at normalised propagation distances: (a) weakly superluminal case $\left(\sqrt{\epsilon}=1.01 n_{L}=3.0\right)$; (b) strongly superluminal case $\left(\sqrt{\epsilon}=2.0 n_{L}=2.5\right)$. In the vertical axis of the figure an arbitrary unit is used to express the relative growth of the $\mathrm{THz}$ amplitude as compared to the pump. 
so-called free- and forced-wave responses [6, 25] supported by first and second terms of nonlinear polarization from the r.h.s. of Eq. (13), and propagating with the velocities $c / \sqrt{\in}$ and $v_{\mathrm{g}}$, respectively. Remarkably, as a consequence of the required velocity-matching condition, the growth rate of the $\mathrm{THz}$ wave amplitude in the weakly superluminal case appears to be faster than that in the strongly superluminal one.

In the case of subluminal excitation of the $\mathrm{THz}$ wave (i. e. when inequality $n_{L}^{2}>\epsilon(\omega)$ holds) the existing singularity in the frequency dependence of $\epsilon(\omega)$ plays a crucial role. As the analytical solution for Eq. (9) encounters numerous obstacles, we evaluated $\mathrm{THz}$ generation dynamics in this case numerically. For this evaluation, as in the superluminal case, we take propagation parameters $\left(\sqrt{ } \in=0.95 n_{L}=3.2\right)$ close to those in semiconductor crystals, typically used for experiments. Results of the numerics for the subluminal case of polarisation propagation are given in Fig. 4 .

Comparing the last (3 and 4) Figures the appearance of oscillations running in front and back of the main $\mathrm{THz}$ pulse should be noted as the most prominent feature characteristic of subluminal propagation of the $\mathrm{THz}$ polarisation source. These oscillations propagating faster and slower than the optical pulse are the phonon polaritons arising above and below the intersection (velocity-matching) point as it is sketched in Fig. 2.

\section{Conclusions}

In conclusion, the present study emphasises that the two-photon resonance enhanced four-wave mixing is

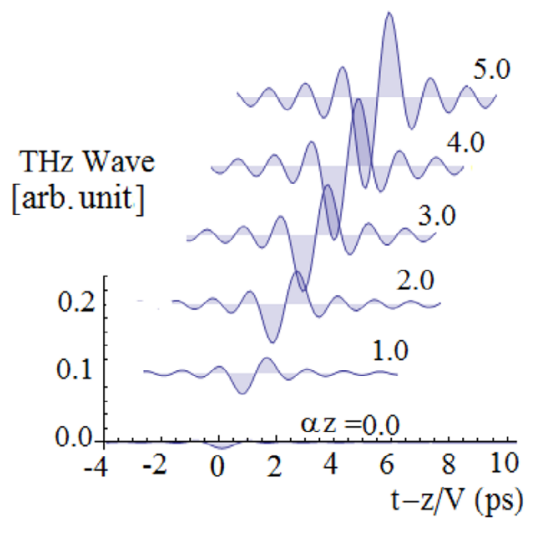

Fig. 4. (Colour online) Dynamics of THz radiation generation under subluminal $\left(\sqrt{\epsilon}=0.95 n_{L}=3.2\right)$ propagation of THz polarization source given by Eq. (7). Amplitudes of $\mathrm{THz}$ radiation are shown in the vertical offsets at normalised propagation distances $K_{2} z$. In the vertical axis the arbitrary unit is used to express the relative growth of the $\mathrm{THz}$ amplitude as compared to the pump. a promising technique that could extend the methods of $\mathrm{THz}$ radiation generation by $\mathrm{OR}$ in centrosymmetric media.

It is important to remember that the non-depleted pump approximation was used in Section 2 when evaluating induced polarisation $\rho_{12}$. Therefore, a more 5 comprehensive analysis is needed for the precise evaluation of the conversion efficiency of the method. Meanwhile, the results presented herewith substantiate the originally proposed scheme of the OR method offering the strategy of a design and making new materials for it.

One of the possible directions comes from mature semiconductor manufacturing technologies, such as quantum dots in semiconductor nanoparticles. It is known that resonant interaction with optical light fields is strongly enhanced here in comparison with atomic systems due to the quantum confinement effect [27, 28]. Indeed, nonlinear optical experiments demonstrating clear signatures of coherent interaction can be performed here with pulses of hundreds of femtoseconds and even longer. Taking into account enhanced optical transitions to excitonic and bi-excitonic states [29, 30], intensities for the SIT at two-photon resonance should be reduced to hundreds and even tens of $\mathrm{MW} / \mathrm{cm}^{2}$ compared to the scale of $\mathrm{GW} / \mathrm{cm}^{2}$ which is characteristic for of SIT at two-photon resonance in atomic systems. Finally, considering the possible ranges of the two-photon absorption coefficient $K_{2}$ of the media of interest in the range from tens to several $\mathrm{cm} / \mathrm{MW}$, one should consider $100 \mu \mathrm{m}$ as a reasonable distance for the observation of $\mathrm{THz}$ radiation generation using the proposed method.

\section{Acknowledgements}

The work was financially supported by the Research Council of Lithuania under the bilateral LithuaniaBelarus collaboration programme in science and technology (project No. TAP LB 03/2013).

\section{References}

[1] D.G. Auston and P.R. Smith, Generation and detection of millimeter waves by picosecond photoconductivity, Phys. Rev. Lett. 43(16), 631-633 (1983).

[2] D.G. Auston, K.P. Cheung, J.A. Valdmanis, and D.A. Kleinman, Cherenkov radiation from femtosecond optical pulses in electro-optic media, Phys. Rev. Lett. 53(16), 1555-1558 (1984).

[3] L. Xu, X.-C. Zhang, and D.H. Auston, Terahertz beam generation by femtosecond optical pulses in electrooptic materials, Appl. Phys. Lett. 61, 17841786 (1992). 
[4] F. Blanchard, G. Sharma, and L. Razzari, et al., Generation of intense terahertz radiation via optical methods, IEEE J. Sel. Top. Quantum Electron. 17(1), 5-16 (2011).

[5] J.A. Flp, L. Palfalvi, S. Klingebiel, G. Almasi, F. Krausz, S. Karsch, and J. Hebling, Generation of sub-mJ terahertz pulses by optical rectification, Opt. Lett. 37, 557-559 (2012).

[6] K.L. Vodopyanov, Optical generation of narrowband terahertz packets in periodically-inverted electro-optic crystals: conversion efficiency and optimal laser pulse format, Opt. Express 14, 22632276 (2006).

[7] K.L. Vodopyanov, Optical $\mathrm{THz}$ wave generation with periodically-inverted GaAs, Laser Photon. Rev., 14, 2263-2276 (2006).

[8] M. Jewariya, M. Nagai, and K. Tanaka, Enhancement of terahertz wave generation by cascaded $\chi^{(2)}$ processes in $\mathrm{LiNbO}_{3}$, J. Opt. Soc. Am. B 26(9), A101-A103 (2009).

[9] A. Bugay and S. Sazonov, The generation of terahertz wave radiation via optical rectification in the self-induced transparency regime, Phys. Lett. A 374, 1093-1096 (2010).

[10] J. Hebling, K.-L. Yeh, M.C. Hoffmann, B. Bartal, and K.A. Nelson, Generation of high-power terahertz pulses by tilted-pulse-front excitation and their application possibilities, J. Opt. Soc. Am. B 25(7), 6-19 (2008).

[11]I. Pop and L. Moorman, Electromagnetically induced generation, gain in delayed wave mixing, and measuring coherent states using quantum-interference windows, Phys. Rev. A 60, 678-686 (1999).

[12] M.M. Kash, V.A. Sautenkov, A.S. Zibrov, L. Hollberg, G.R. Welch, M.D. Lukin, Y. Rostovtsev, E.S. Fry, and M.O. Scully, Ultraslow group velocity and enhanced nonlinear optical efffects in a coherently driven hot atomic gas, Phys. Rev. Lett. 82, 5229-5232 (1999).

[13]J. Mompart and R. Corbalan, Lasing without inversion, J. Opt. B Quantum Semiclass. 2(3), R7 (2000).

[14]E. Gaižauskas, D. Pentaris, T. Efthimiopoulos, and V. Vaicaitis, Probing electronic coherences by combined two- and one-photon excitation in atomic vapors, Opt. Lett. 38, 124-126, (2013).

[15]I.A. Poluektov, Yu.M. Popov, and V.S. Roitberg, Coherent effects in the propagation of ultrashort light pulses in resonant media. Part II (Review), Sov. J. Quant. Electr. 4(6), 719-739 (1974).

[16]I.A. Poluektov, Yu.M. Popov, and V.S. Roitberg, Self induced transparency effect, Sov. Phys. Usp 17(5), 673-690 (1975).

[17]E. Gaižauskas and G. Gedvilas, Theory of coherent oneand two-photon interaction in a three-level system, Opt. Commun. 91(34), 312-320 (1992).
[18] O. Kittelmann, J. Ringling, A. Nazarkin, G. Korn, and I.V. Hertel, Direct observation of coherent medium response under the condition of twophoton excitation of krypton by femtosecond uv-laser pulses, Phys. Rev. Lett. 76, 2682-2685 (1996).

[19]E. Gaizauskas and L. Valkunas, Femtosecond four-wave mixing spectroscopy of molecular aggregates, J. Phys. Chem. B 101(37), 7321-7326 (1997).

[20] A. Nazarkin, G. Korn, O. Kittelmann, J. Ringling, and I.V. Hertel. Femtosecond-pulse two-photon resonant difference-frequency mixing in gases: a technique for tunable vacuum-ultraviolet femtosecond-pulse generation and a spectroscopic tool for studying atoms in strong laser fields, Phys. Rev. A 56, 671-684 (1997).

[21] A. Nazarkin and G. Korn, Coherent propagation effects and pulse self-compression under the conditions of twophoton resonant difference-frequency generation, Phys. Rev. A 56, 5187-5190 (1997).

[22]D. Grischkovsky, M.M.T. Loy, and P.F. Liao, Adiabatic following model for two-photon transitions: Nonlinear mixing and pulse propagation, Phys. Rev. A 12(6), 2514-2533 (1975).

[23] J.-C. Diels and A.T. Georges, Coherent two-photon resonant third- and fifth-harmonic vacuumultraviolet generation in metal vapors, Phys. Rev. A 19(4), 1589-1906 (1979).

[24] N.N. Zinov'ev, A.S. Nikogosian, and J.M. Chamberlain, Terahertz radiation from a nonlinear slab transversed by an optical pulse, Phys. Rev. Lett. 98, 044801 (2007).

[25] M.I. Bakunov, S.B. Bodrov, A.V. Maslov, and M. Hangyo, Theory of terahertz generation in a slab of electro-optic material using an ultrashort laser pulse focused to a line, Phys. Rev. B 76(8), 085346 (2007).

[26] A. Schneider, Theory of terahertz pulse generation through optical rectification in a nonlinear optical material with a finite size, Phys. Rev. A 82, 033825 (2010).

[27] P. Chen, C. Piermarocchi, and L.J. Sham, Control of exciton dynamics in nanodots for quantum operations, Phys. Rev. Lett. 87(6), 067401 (2001).

[28]E. Hanamura, Very large optical nonlinearity of semiconductor microcrystallites, Phys. Rev. B 37, 1273-1279 (1988).

[29] J. Kasprzak and W. Langbein, Coherent response of individual weakly confined exciton-biexciton systems, J. Opt. Soc. Am. B 29(7), 1766-1771 (2012).

[30] C.M. Tu, S.A. Ku, W.C. Chu, C.W. Luo, J.C. Chen, and C.C. Chi, Pulsed terahertz radiation due to coherent phonon-polariton excitation in $\langle 110\rangle \mathrm{ZnTe}$ crystal, J. Appl. Phys. 112(9), 093110 (2012). 


\title{
TERAHERCUU SPINDULIUOTĖS GENERAVIMAS NAUDOJANT SKIRTUMINIO DAŽNIO MAIŠYMĄ ESANT VIENFOTONIAM IR DVIFOTONIAM REZONANSAMS
}

\author{
E. Gaižauskas ${ }^{\text {a }}$ O. Balachninaite ${ }^{\text {a }}$, O. Khasanov ${ }^{\text {b }}$ \\ ${ }^{\text {a } V i l n i a u s ~ u n i v e r s i t e t o ~ L a z e r i n i u ~ t y r i m u ~ c e n t r a s, ~ V i l n i u s, ~ L i e t u v a ~}$ \\ ${ }^{\mathrm{b}}$ Baltarusijos mokslų akademijos Mokslinis-praktinis medžiagotyros centras, Minskas, Baltarusija
}

\begin{abstract}
Santrauka
Darbe teoriškai tiriama skirtuminio dažnio generavimo terahercų bangų ruože dinamika, naudojant keturbangị maišymą kvantiniame trijų lygmenų sistemų ansamblyje. Trijų lygmenų sistema šalia draustino (dipoliniu artiniu) šuolio iš pagrindinès i aukščiausią būseną turi ir optiškai aktyvų žemo dažnio šuoli i vibracinę būseną (fononą). Surištoji koherentinè elektromagnetinio lauko ir fononu būsena (poliaritoninè banga) sukuriama kaupinant skirtingų dažnių ultratrumpaisiais lazeriniais impulsais. Pirmasis dažnis $\omega_{L}$ matomame ar artimajame infraraudonųjų bangų ruože parenkamas taip, kad būtų tenkinama dvifotonio rezonanso sąlyga,
\end{abstract}

o antrasis $\omega_{P}$ - artimas dvigubam kaupinimo dažniui $\left(\omega_{P} \sim 2 \omega_{L}\right)$. Kaupinimo artiniu įvertinta terahercu bangos generavimo dinamika demonstruoja optinio lyginimo (optical rectification, angl.) metodo realizavimo galimybes terpèse su centrine simetrija. Praktiškai pasiūlytas metodas galètų būti taikomas technologiškai patraukliose optinio stiklo su iterptomis puslaidininkiu nanodalelèmis terpèse, kurioms būdingi optiniai šuoliai i eksitonines būsenas, pasižymintys dideliu osciliatorių stipriu, o sužadinti koherentiniai eksitonai - ilga gyvavimo trukme, palyginti su ultratrumpujjų kaupinančių impulsų trukmèmis. 